\title{
Optimisation-Based Power Management System for an Electric Vehicle with a Hybrid Energy Storage System
}

\author{
S. Gonsrang ${ }^{1,2 *}$ and R. Kasper ${ }^{1}$ \\ ${ }^{1}$ Institute of Mobile Systems, Otto-von-Guericke-University Magdeburg, Building 10, \\ Universitätsplatz 2, 39106 Magdeburg, Germany \\ ${ }^{2}$ Department of Mechanical Engineering, Faculty of Engineering, Prince of Songkla \\ University, Songkhla 90112, Thailand \\ *Email: gsarawut@eng.psu.ac.th \\ Phone: +66-7428-7228; Fax: +66-7455-8830
}

\begin{abstract}
Hybridisation of energy storage sources is necessary for extending mileage of electric vehicles. However, coordination of multiple devices with different characteristics is challenging. This paper presents a power management system (PMS) for an electric car equipped with a battery pack, supercapacitor bank, and range extender. The proposed PMS deals with vehicular load distribution by solving a power management problem, formulated as a constrained quadratic program (CQP). Then, the optimised variables, such as the desired speed and optimised operation points of the car's components, are implemented by controllers at a component level. Complete knowledge about the trip is unwanted because the proposed PMS considers a power management problem only over a controlled horizon of one sampling period. Furthermore, this work varies weight factors to tackle various difficulties, for instance, regenerative power management. The simulation results revealed that the proposed system optimally allocated an electric power load to the car components, without violating any physical constraints. Also, the comparative study showed that the performance of the CQP in power management was comparable to that of the benchmark, based on a nonlinear model predictive control.
\end{abstract}

Keywords: Electric vehicle; hybrid energy storage system; power management system; constrained quadratic program.

\section{INTRODUCTION}

Tailpipe emissions cause many adverse consequences, such as health problems, ozone depletion, and climate change [1]. Also, ever-increasing oil consumption results in economic issues and national security threats in oil-importing countries [2]. Thus, reduction of fuel oil consumption is vital for these countries. Transportation consumes a significant amount of fuel oil among all human activities [3], [4]. So, electric vehicle (EV) utilisation would lead to a reduction of petroleum reliance in these countries. EVs have many attractive advantages over conventional cars. These vehicles can be recharged overnight using electricity derived from renewable sources or high-efficiency power plants. Moreover, they release none of the exhaust gases and perform regenerative brake.

Notwithstanding their striking advantages, EVs still gain little popularity because of insufficient driving ranges and costly batteries [5]. Combinations of batteries and other energy storage devices might help overcome the mentioned disadvantages. Besides fuel cell stacks, compact power generators or range extenders (RE) can not only extend 
mileage but also increase power capabilities of EVs. Range extenders using internal combustion engines (ICE) as power plants are a highly viable technology, compared to their fuel-cell counterparts [5]. Diesel engines have been adapted in a board spectrum of applications, and alternative fuels are most appropriate for use in this type of engines [6]. Alternative fuel research is one most active scientific area. Many scholars try desperately to improve biodiesel's quality and the diesel engine performances [7]-[11], and good track-records of creating new biofuel formulae can be found in the references therein.

In addition to increasing mileage, an ICE-based range extender produces fewer emissions when working in combination with a battery pack and SCs [12]. Also, the range extender's engine operates independently of the car's drivetrain. So, this machine can run steadily at its top performance. For this reason, some sports cars and trucks even employ micro-gas turbine engines as power plants of range extenders [13], [14]. Furthermore, drivers of EVs could save more energy in cold climate by circulating waste heat from the range extenders for cabin heating [15]. Moreover, an average total cost of ownership and maintenance, and repair costs of EVs with hybrid energy storage systems (HESS) are cheaper than those of pure EVs by $11.5 \%$ and $9 \%$, respectively [16]. Although using a HESS in an EV is promising in extending driving range [17], a sophisticated power management system (PMS) is necessary to coordinate multiple energy storage devices.

Rule-based energy management strategies are widely realised in EVs built with HESSs [12], [18]-[20]. These approaches are robust and computationally efficient but cannot guarantee energy conservation. Also, manual parameterisation and engineering expertise are crucial to making the applicable rules. Some governing rules can be extracted from the solutions attained using other optimisation techniques, such as dynamic programming (DP) and genetic algorithm-based optimisation [21]-[23]. However, the extracted rules have a dependency on driving patterns.

A fuzzy logic control is also practised to organise energy usage of hybrid vehicles and extended-range EVs [24], [25]. Fuzzy logic controllers can either work with or reinforce other tools for best outcomes of onboard electricity management [22], [26]. Fuzzy logic controllers can make rational decisions, but energy optimality is not assured. Like rule-based strategies, human expertise and experience are essential for designing the membership functions of a fuzzy controller. Still, various methods have been adapted to solve online power management problems, such as a stochastic DP [27] and a line search method [28]. These algorithms require complete knowledge about the trip.

Convex optimisation can serve many purposes in EV applications, such as component design [29], [30] and energy management [31]-[33]. Convex optimisation algorithms can be integrated with deterministic DP to handle optimisation problems involving discrete decision variables [31]. Quadratic programming integrated with other decision-making programs enhances the energy efficiency of plug-in hybrid EVs [32], [33]. However, the applications of convex optimisation are still limited to obtaining global solutions to optimise problems in vehicles.

A model predictive control can attain optimal control inputs that optimise the future behaviour of the plant [34]. Zhang et al. [35] balanced output power from battery packs and supercapacitors using a linear model predictive control. They adapted a DP to solve the discretised optimisation problem. Xiang et al. [36] presented an energy management strategy for a dual-mode power-split hybrid EV using a nonlinear model predictive control algorithm (NMPC) based on a forward DP. Accurate predictive information is an essential ingredient making a model predictive control method successful in process control. On the other hand, this predicted information necessitates 
the use of sophisticated prediction algorithms. Also, an NMPC becomes computationally inefficient when solving large optimal control problems.

The PMS presented in this paper suited for use in an electric car with a HESS. This system can avoid a high computation burden and is real-time-implementable. The proposed PMS consists of an optimisation and component levels. The former level serves as a master controller. It provides some optimised set-points, which will be executed by the local controllers at the component level. As a result, the car runs at the desired speed with the economical use of driving effort.

An NMPC can deliver a near-optimal control policy; however, it becomes computationally inefficient when solving large nonlinear problems. Thus, this work captures the optimal control problem of the studied EV over a limited control horizon, consisting of only one sampling period. By doing so, complete knowledge about the trip becomes unnecessary, and the problem can be solved even faster. Selecting the range extender's load point is a discrete problem while defining the operation states of a battery pack and SC bank is a continuous one. Previous works considered these problems sequentially using different algorithms. So, the obtained results might not be globally optimum. Instead, this work formulates the problem under consideration as one static optimisation problem, in the form of a mixed-integer quadratically-constrained quadratic program [37]. This program can handle optimisation problems involving both continuous and discrete variables. So, it allows for selecting the operation states of all energy storage devices concurrently. Moreover, while other works solely define fixed-value weight factors, this work varies these manipulating parameters to tackle difficulties, such as the distribution of regenerative power among energy storage devices. The performance of the proposed PMS was verified under differing driving scenarios through intensive computer simulation. A comparative study was carried out between the proposed optimisation program and the benchmark based on an NMPC [34].

\section{VEHICLE MODELLING}

From Figure 1, the traction motor generates driving torque. Then, the single-ratio gearbox transmits driving torque to the rear wheels. Mechanical brakes cooperate with the motor to decelerate the car. A supercapacitor (SC) bank helps provide high power for the car. A range extender charges up the battery pack while driving. Each subsystem is controlled by its control system to follow the optimised set-points.

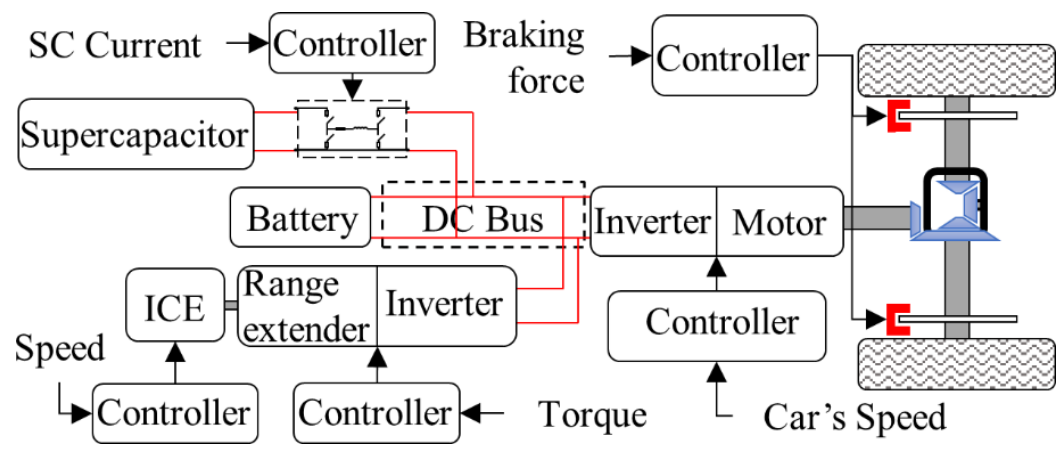

Figure 1. A diagram depicting the vehicular topology of the studied car, the set-points, and local controllers of the major components. 
In the following models, all parameters are considered constant. The overall control strategy in use will adopt long-term parameter variations or operation point dependencies. However, this paper neglects the temperature dependencies of parameters for simplicity. Note that reference [38] presents more generic governing equations of a vehicle which are useful for the formulation of an energy management problem.

\section{Vehicle Body and Traction Motor}

The forward longitudinal movement of the car with the mass of $m_{V}$ is described by:

$$
m_{V} \dot{V}=F_{M}-F_{B r k}-F_{g}(\theta)-F_{W}(\hat{V})
$$

The right-hand side of Eq.(1) sums up the following forces: the traction force produced by the electrical drive, $F_{M}$; the braking force, $F_{B r k}$; the parallel component of the car weight on an incline, $F_{g}$; and the aerodynamic drag, $F_{W}$. The speed $\hat{v}$ is the car speed relative to wind speed, and $\theta$ is the inclination angle. The resultant force causes the vehicle speed $\mathrm{v}$ to change at the rate of $\dot{v}$. The force $F_{M}$ and the applied voltage of the motor, $U_{M}$, obey the following expressions, respectively:

$$
\begin{aligned}
& F_{M}=\left(k_{M} I_{M^{-}}\left(J_{V} G / r_{W}\right) \dot{v}-\left(d_{V} G / r_{W}\right) v\right)\left(G / r_{W}\right) \\
& U_{M}=R_{M} I_{M}+\left(k_{M} G / r_{W}\right) v
\end{aligned}
$$

where $k_{M}$ is the motor constant, $G$ is the gear reduction ratio, $r_{W}$ is the wheel radius, $R_{M}$ is the motor resistance, $I_{M}$ is the motor current, and $J_{V}$ and $d_{V}$ are the inertia and damping of the drivetrain, respectively. The dynamic of $I_{M}$ dies away quickly because of a welldesigned current controller. So, it is deleted from Eq. (3). The tractive power demand, $P_{M}$, is computed using:

$$
P_{M}=\left(k_{M} G / r_{W}\right) v I_{M}+\left(R_{I n v, M}+R_{M}\right) I_{M}^{2}
$$

The parameter $R_{I n v, M}$ is the equivalent resistance of power inverter.

In this work, the EV model is based on the BMWi3 REx with 64-Ah Li-ion battery pack [39]. The motor torque, $M_{M, l i m}$, of the studied car is limited by:

$$
M_{M, \text { lim }}=\left\{\begin{array}{c}
\left(P_{M, \max } r_{W} / G\right)(1 / \mathrm{v})-68.2\left(1-\left(500 r_{W} / G\right)(1 / \mathrm{v})\right) \\
\left(G / r_{W}\right) v>500 \mathrm{rad} / \mathrm{s} \\
M_{M, \text { max }} \text { Otherwise }
\end{array}\right.
$$

where $M_{M, \max }$ is the peak output torque, and $P_{M, \max }$ is the maximum power output. This study assumes that the car control system supplies online estimations about vehicle mass, dynamic wheel radius, friction constants, etc., to retain reasonably accurate modelling.

\section{Battery Pack}

The battery terminal voltage, $U_{B}$, is described by

$$
U_{B}=E_{B}+I_{B} R_{B}=E_{B}+\dot{Q}_{B} R_{B}
$$


where $R_{B}$ is the internal resistance, $E_{B}$ is the open circuit voltage, and $Q_{B}$ is the battery electric charge. A derivative of the state of charge and the battery discharged power, denoted by $\operatorname{So}_{B}$ and $P_{B}$, respectively, is approximated by:

$$
\begin{aligned}
& \dot{\operatorname{SoC}_{B}}=\left(1 / Q_{B, \text { max }}\right) I_{B} \\
& P_{B}=E_{B} I_{B}+R_{B} I_{B}^{2}
\end{aligned}
$$

The variable $I_{B}$ and $Q_{B}$ are the battery current and maximum battery electric charge, respectively. Note that, a battery management system is assumed to be in use. It maintains the battery pack in safe operation, as well as estimating the state of charge for consideration in the proposed PMS.

\section{Supercapacitors}

The SC bank model consists of one large capacitor with the capacitance of $C_{S C}$ and two resistors. One resistor with the resistance of $R_{S C, p}$ is in parallel and the other resistor with the resistance of $R_{S C, S}$ is in series. The following equations explain the relationships between the energy level, $U_{C}$, current, $I_{S C}$, terminal voltage, $U_{S C}$, of the $S C$ bank, and the $\mathrm{SC}$ power to the DC bus, $P_{S C}$, respectively:

$$
\begin{aligned}
& I_{S C}=C_{S C} \dot{U}_{C}+\left(1 / R_{S C, p}\right) U_{C} \\
& U_{S C}=U_{C}+R_{S C, S} I_{S C} \\
& P_{S C}=U_{C} I_{S C}+\left(R_{S C, S}+R_{\text {Conv }}\right) I_{S C}^{2}
\end{aligned}
$$

where $R_{C o n v}$ is the equivalent resistance of the SC converter--a DC/DC converter is necessary to decouple the $\mathrm{SC}$ voltage from that of the DC bus. The current $I_{S C}$ flows from the SC bank through the converter.

This work varies the SC electric charge concerning the car's kinetic energy (KE) as realised in references [40], [41]; the governing equation of the SC energy level, $U_{C, K E}$, is as follows:

$$
U_{C, K E}(V)=\left(U_{C, \max }^{2}-\left(k_{S C, K E} m_{V} / C_{S C}\right) \max \left(0, V^{2}-V_{o f f}^{2}\right)\right)^{1 / 2}
$$

The factor $k_{S C, K E}$ is the ratio of $\mathrm{KE}$ at the maximum velocity, $v_{\max }$, to the total energy that the SC bank can absorb, and $U_{C, \max }$ is the SC maximum voltage. The $U_{C, K E}$ will be equated with $U_{C, \max }$ if the car runs slower than the off-set speed, $v_{o f f}$. The fraction $k_{S C, K E}$ is acquired by solving the right-hand side of Eq.(12) after substituting $v$ by $v_{\max }$.

\section{Range Extender}

The engine exhibits transient behaviours, which are not modelled explicitly in the optimisation problem. Instead, it is regarded as an energy storage device, which can deliver electricity instantly to the DC bus if the engine has started and is at least idling. 
Table 1. Range extender's choices. This power generator is at rest if $n_{R E, 1}$ is selected.

\begin{tabular}{lccccc}
\hline & $n_{R E, 2}$ & $n_{R E, 3}$ & $n_{R E, 4}$ & $n_{R E, 5}$ & $n_{R E, 6}$ \\
\hline Engine speed (rad/s) & 126 & 220 & 220 & 251 & 251 \\
Generator torque (Nm) & 22 & 72 & 90 & 94 & 118 \\
Fuel consumption $(\mathrm{g} / \mathrm{s})$ & 0.198 & 0.927 & 1.135 & 1.320 & 1.645 \\
Net efficiency (\%) & 24.0 & 33.3 & 35.1 & 35.5 & 36.0 \\
\hline
\end{tabular}

In this work, the range extender can operate at five different rates, as presented in Table 1. Fuel economy and inertia effect are significant concerns in selecting load points from the fuel consumption map of the 2-L, 4-stroke Volkswagen engine [42]. This work utilises six binary variables to represent on-off states of the load points: $\mathbf{n}_{\mathbf{R E}}=\left\{\mathrm{n}_{\mathrm{RE}, 1}, \ldots, \mathrm{n}_{\mathrm{RE}, 6}\right\}$ and $\mathrm{n}_{\mathrm{RE}, \mathrm{i}} \in\{0,1\}$. The sum of the binary variables must be one since the range extender can work at one operation at a time:

$$
\sum_{i=1}^{6} n_{R E, i}=1, n_{R E, i} \in\{0,1\}
$$

The range extender output power, $P_{R E}$, the rate of heat removal from the ICE, $\dot{Q}_{I C E}$, and the rate of fuel consumption, $\dot{m}_{R E}^{\text {fuel }}$, are respectively described as follows:

$$
\begin{aligned}
& P_{R E}=\sum_{i=1}^{6}\left(\left(R_{I n v, R E} / k_{R E}^{2}\right) M_{R E, i}^{2}-M_{R E, i} N_{R E, i}\right) n_{R E, i} \\
& \dot{Q}_{I C E}\left(\boldsymbol{n}_{R E}\right)=\sum_{i=1}^{6}\left(h_{f u e l} \dot{m}_{R E, i}^{\text {fuel }}-M_{R E, i} N_{R E, i}\right) n_{R E, i} \\
& \dot{m}_{R E}^{\text {fuel }}=\sum_{i=1}^{6} \dot{m}_{R E, i}^{\text {fuel }} n_{R E, i}
\end{aligned}
$$

where $M_{R E}$ is the torque produced by the generator (Figure 1), $N_{R E}$ is the engine angular speed, $k_{R E}$ is the generator torque constant, $R_{I n v, R E}$ is the power inverter resistance, $h_{f u e l}$ is the heating value of fuel oil, and $\dot{m}_{R E, i}^{f u e l}$ is the fuel consumption rate at a given operation.

\section{Bus}

The car's auxiliary equipment consumes $580 \mathrm{~W}$, denoted by $P_{A u x}$; and a thermal load of the passenger cabin is $1200 \mathrm{~W}$, denoted by $P_{t h e}$. These parameters are adapted from reference [15]. The algebraic sum of the powers of electric components is:

$$
P_{B}+P_{M}+P_{S C}+P_{R E}+P_{A u X}+P_{\text {the }}=0
$$




\section{POWER MANAGEMENT SYSTEM}

\section{Problem Formulation}

The optimisation problem involves multiple objectives needing to be satisfied simultaneously. Firstly, the car must fulfil driver's demand with trade-off use of driving effort without violation of any physical constraints. Secondly, $U_{S C}$ should converge to $U_{C, K E}$. Lastly, the range extender should assist the battery pack when peak power demand happens. The solution to the optimization problem can be attained indirectly using a cost function, consisting of multiple weighted costs [28], [36].

\section{Nonlinear model predictive control-based program}

Let $\Delta \mathrm{T}$ denotes a sampling period. The sampling points in time, $t_{k}$, are given as $t_{0}+$ $k \Delta T, k=1,2, \ldots$. The predictive horizon is $T_{P}=N \Delta T$, where $N$ is the number of predictive steps. The state and open-loop control value vector become $\boldsymbol{x}_{d}=$ $\left[I_{M}, v, Q_{B}, U_{C}\right]^{T}$ and $\boldsymbol{u}_{d}=\left[U_{M}, F_{B r k}, U_{B}, U_{S C}\right]^{T}$, respectively; the subscript $d$ indicates that all the entries of in the vectors $\boldsymbol{x}_{d}$ and $\boldsymbol{u}_{d}$ are discrete-time variables. Note that this work compares all penalties on a power basis. The performance measure for the control problem at a given time $t_{k}$ is defined as follows:

$$
\begin{aligned}
& J\left(\boldsymbol{x}_{d}, \boldsymbol{u}_{d}, t_{k}\right)=(0.5 / \Delta T)\left(w_{v} m_{V}\left(v-v_{r e f}\right)^{2}+w_{U_{C}} C_{S C}\left(U_{C^{-}} U_{C, K E}\right)^{2}\right) \\
& +w_{I_{M}} R_{M} I_{M}^{2}+w_{I_{S C}} R_{S C, S} I_{S C}^{2}+w_{F_{B r k}} F_{B r k} V_{r e f}
\end{aligned}
$$

The constant $w$ is the weight factor. According to a nonlinear model predictive control explained in reference [34], this work defines a terminal cost for penalizing the errors between $v$ and $v_{r e f}$, and $U_{S C}$ and $U_{C, K E}$ at the last step of predictive calculation:

$$
F\left(\boldsymbol{x}_{d}, t_{k}+T_{P}\right)=(0.5 / \Delta T)\left(w_{v} m_{V}\left(v-v_{r e f}\right)^{2}+w_{U_{C}} C_{S C}\left(U_{C^{-}} U_{C, K E}\right)^{2}\right)
$$

Then, the discrete-time optimal control problem over the predictive horizon becomes:

$$
\begin{aligned}
& J_{N}^{*}=\min _{\boldsymbol{u}_{d}}\left(F_{k+N}\left(\boldsymbol{x}_{d, N}\left(\boldsymbol{x}_{k}\right)\right)+\sum_{i=0}^{i=N-1} J_{k+i}\left(\boldsymbol{x}_{d, k+i}\left(\boldsymbol{x}_{k}\right), \boldsymbol{u}_{d, i}\right) \Delta T\right) \text { s.t. } \\
& \left\{\begin{array}{c}
I_{M}^{+}=-\left(\left(k_{M} G / r_{W}\right) v-U_{M}\right)\left(1 / R_{M}\right) \\
v^{+}=v-\Delta T\left(G^{2} J_{M}+m_{V} r_{W}^{2}\right)^{-1} \times \ldots \\
\left(G^{2} d_{V} v-r_{W} G k_{M} I_{M}^{+}+\left(F_{B r k}+F_{g}(\theta)+F_{W}(\hat{v})\right) r_{W}^{2}\right) \\
Q_{B}^{+}=Q_{B}-\left(\Delta T / R_{B}\right)\left(E_{B}-U_{B}\right) \\
U_{C}^{+}=U_{C^{-}} \Delta T\left(C_{S C} R_{S C, S}\right)^{-1}\left(\left(\left(R_{S C, s}+R_{S C, p}\right) / R_{S C, p}\right) U_{C^{-}} U_{S C}\right)
\end{array}\right.
\end{aligned}
$$




$$
\left\{\begin{array}{c}
-M_{\max } \leq k_{M} I_{M^{-}}\left(d_{M} G / r_{W}\right) v \leq M_{\max } \\
I_{B, M, \max } \leq\left(U_{B}-E_{B}\right)\left(1 / R_{B}\right) \leq I_{B, P, \max } \\
-I_{S C, \max } \leq\left(U_{S C^{-}} U_{C}\right)\left(1 / R_{S C, S}\right) \leq I_{S C, \max } \\
\left(\left(1 / R_{S C, s}\right)\left(U_{S C^{-}} U_{C}\right) U_{S C}+\left(R_{C o n v} / R_{S C, S}\right)\left(U_{S C^{-}} U_{C}\right)^{2}\right)+\left(1 / R_{B}\right) \ldots \\
\left(U_{B^{-}} E_{B}\right) U_{B}+I_{M} U_{M}+R_{I n v, M} I_{M}^{2}+P_{A u x}+P_{t h e}=0
\end{array}\right.
$$

An optimal control sequence, $\boldsymbol{u}_{d}^{*}$, for the above problem is attained using an NMPC routine, described in reference [34]. This NMPC algorithm updates control outputs regarding current states and predictive dynamics of the controlled system. Also, it is robust against perturbations and parameter changes. However, this method requires high computation effort, so it is unsuitable for real-time applications. Thus, the NMPCbased program serves as a baseline for evaluating the performance of the next program.

\section{Constrained quadratic program (CQP)}

The control problem is reconsidered only over $\Delta T: T_{P}=\Delta T$, in this section. By doing so, the optimization problem becomes independent of a driving cycle altogether and can be solved faster. The physical restrictions of the car's components still stringently obey the same expressions used in the previous formulation. However, the range extender operation selection and the power allocation problem will be determined simultaneously. Thus, the decision-variable vector becomes $\boldsymbol{y}_{d}=\left[I_{B}, I_{M}, I_{S C}, F_{B r k}, v, U_{C}, \boldsymbol{n}_{R E}\right]^{T}$. This work imposes the penalty function in a nonconvex quadratic form [43] as follows:

$$
\begin{aligned}
& J\left(\boldsymbol{y}_{d}\right)=(0.5 / \Delta T)\left(w_{v} m_{V} \times\left(v-v_{r e f}\right)^{2}+w_{U_{C}} C_{S C} \times\left(U_{C^{-}}\right.\right. \\
& \left.\left.U_{C, K E}\right)^{2}\right)+w_{I_{M}} R_{M} I_{M}^{2}+w_{I_{S C}} R_{S C, S} I_{S C}^{2}+w_{F_{B r k}} F_{B r k} V_{r e f}+w_{Q_{I C E}} \dot{Q}_{I C E}\left(\boldsymbol{n}_{R E}\right)
\end{aligned}
$$

The minimizer, $\boldsymbol{y}_{d, k+1}^{*}$, is attained by solving the following optimization program:

$$
\begin{aligned}
& J_{k+1}^{*}=\min _{\boldsymbol{y}_{d, k+1}} J_{k+1}\left(\boldsymbol{y}_{d, k+1}\right) \Delta T \text { s.t. } \\
& \left\{\begin{array}{c}
\left.-\left(\left(U_{V} G^{2} / r_{W}\right)+m_{V}\right) / \Delta T\right)\left(V_{k+1}-V_{k}\right)+\left(k_{M} G / r_{W}\right) I_{M, k+1}-\ldots \\
\left(d_{V} G^{2} / r_{W}\right) v_{k+1}-F_{B r k, k+1}-F_{g}\left(\theta_{k}\right)-F_{W}\left(\widehat{v}_{k}\right)=0 \\
I_{S C, k+1}=\left(C_{S C} / \Delta T\right)\left(U_{C, k+1}-U_{C, k}\right)+\left(1 / R_{S C, p}\right) U_{C, k+1} \\
U_{C, k}=U_{S C, k}-R_{S C, S} I_{S C, k} \\
\sum_{i=1}^{6} n_{R E, i, k+1}=1 \\
\left(E_{B, k+1}+R_{B} I_{B, k+1}\right) I_{B, k+1}+\left(\left(k_{M} G / r_{W}\right) v_{k+1}+\left(R_{M}+R_{I n v, M}\right) I_{M, k+1}\right) \ldots \\
I_{M, k+1}+\left(U_{C, k+1}+\left(R_{S C, S}+R_{C o n V}\right) I_{S C, k+1}\right) I_{S C, k+1}+\ldots \\
\sum_{i=1}^{6}\left(\left(R_{i n v, R E} / k_{R E}\right) M_{R E, i}^{2}-M_{R E, i} N_{R E, i}\right) n_{R E, k+1, i}+P_{A u x}+P_{t h e}=0
\end{array}\right.
\end{aligned}
$$




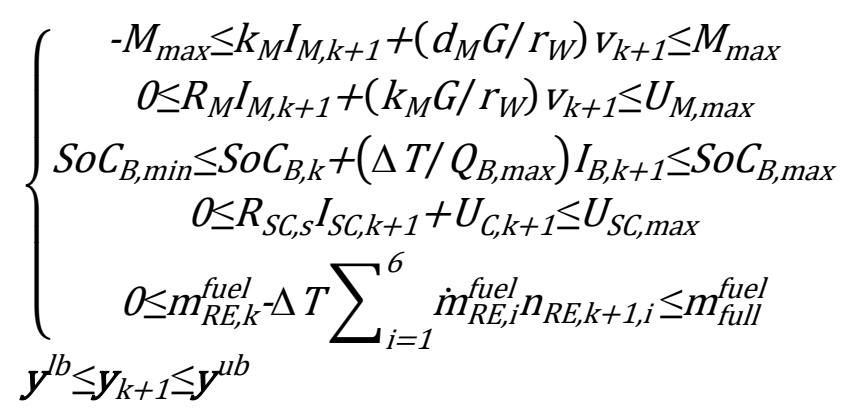

The above problem is a mixed integer quadratically constrained quadratic program. According to the standardised format [43], the quadratic constraint in Eq.(22) must be convex. Therefore, it is modified by substituting $v_{k+1}$ with $v_{k}+\left(v_{r e f, k+1}-\right.$ $\left.v_{r e f, k}\right), E_{B}$ with $U_{B, k}-R_{B} I_{B, k}$, and $U_{C}$ with $U_{C, K E}$. SCIP is adopted to solve the proposed CQP for a minimizer, $\boldsymbol{y}_{d, k+1}^{*}$; this solver combines state-of-the-art techniques for handling constraint integer problems [37].

\section{Power Management System}

This section briefly explains the design features of the proposed PMS. Figure 2 presents the structure of the proposed PMS comprising an optimisation level (a master controller) and a component level. The master controller provides the component level with decent set-points. Local controllers at the component level regulate the car's components so that these components keep track of the optimised inputs.

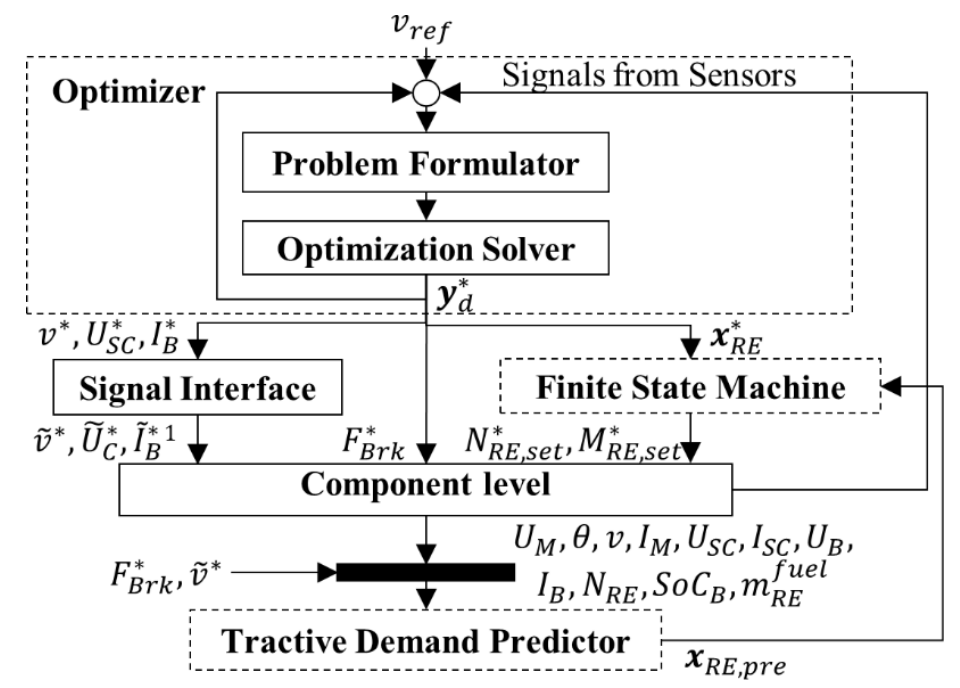

Figure 2. The structure of the PMS. Dashed boxes enclose discrete-time systems, and solid boxes contain continuous-time systems. A tilde ( ) over a variable shows that the signal interface has linearly interpolated such variable for smooth control effect.

\section{Optimisation level}

The optimisation level consists of the optimiser and other auxiliary units, such as the signal interface, finite state machine, and tractive demand predictor. When the optimiser is executed, the optimisation problem is numerically formulated concerning present values of the requested speed, inclination angle and wind speed, and present states of the 
car's components. Note that all the component states are bounded inside the permissible ranges to prevent the optimiser from making an irrational decision. After that, the optimisation solver solves the problem for the minimiser, $\boldsymbol{y}_{d}^{*}$.

The signal interface linearly interpolates $v^{*}, U_{C}^{*}$, and $I_{B}^{*}$ and passes them to the local controllers. A Kalman-filter-based power demand predictor estimates electric power demanded by the motor and the SC bank for half a second ahead. Then, it will generate a starting command for the range extender if the predicted power demand outweighs the battery's capacity. The finite state machine combines the startup commands from the optimizer and the predictor and operates the onboard generator accordingly.

\section{Component level}

A vehicle speed, braking force, engine speed, and generator torque controller regulate the car's components regarding $\tilde{v}^{*}, F_{B r k}^{*}, N_{R E}^{*}$, and $M_{R E}^{*}$, respectively. These controllers are closed-loop control systems, but a brake controller is an open-loop one.

In this work, the SC bank serves as an auxiliary component. It compensates all additional power demands caused by imprecise driving environment and a mismatch between the mathematic model and the real car. This auxiliary device is regulated by a closed-loop controller as well. The SC current set-point is determined using the following expression:

$$
\begin{aligned}
& I_{S C}=\left(0.5 / R_{C o n v}\right)\left(-U_{S C}\left(U_{S C}^{2}+4\left(U_{B} \tilde{I}_{B}^{*}+P_{S C}\right) R_{C o n v}\right)^{1 / 2}\right) \\
& +\left(\widetilde{U}_{C}^{*}-U_{C}\right)\left(C_{S C} / T_{S C}\right)+\left(1 / R_{S C, p}\right) U_{C}
\end{aligned}
$$

Noted that $\mathrm{P}_{\mathrm{SC}}=\mathrm{P}_{\mathrm{M}}+\mathrm{P}_{\mathrm{RE}}+\mathrm{P}_{\mathrm{Aux}}+\mathrm{P}_{\text {the }}$. The parameter $T_{S C}$ is a compensation time constant. The first term in Eq.(23) determines a major part of the SC current. The second term calculates a compensation current for maintaining the SC charge level close to $\widetilde{U}_{C}^{*}$. The last term approximates the SC current leakage.

\section{Weight factor tuning}

The weight factor adjustment was performed under the new European driving cycle (NEDC). The NEDC consists of several trapezoidal-shape speed trajectories, which make it easy to recognise changes stemming from varying weight factors. The tuning steps are as follows:

i. All values of the weight factors should be one at the beginning.

ii. The factor $w_{v}$ should be increased with an increment of ten until the car keeps pace with the reference speed accurately.

iii. The factor $w_{I_{M}}$ can be kept at one. Reducing $w_{I_{M}}$ results in faster acceleration. However, $w_{I_{M}}$ must be nonzero; otherwise, the traction motor exhibits oscillation.

iv. The ratio of $w_{F_{B r k}}$-to- $w_{I_{M}}$ should be around 0.5-0.7 to maximize regenerative power.

v. An increment of 0.1 can be used for tuning $w_{U_{C}}$ to find a value that keeps $U_{C}$ close to $U_{C, K E}$. 
vi. The SC voltage $U_{C}$ will convert to $U_{C, K E}$ speedily, provided that $w_{I_{S C}}$ is lower than one. However, the factor $w_{I_{S C}}$ should be greater than 0.1 to avoid a current overshoot.

vii. The factor $w_{q_{I C E}}$ should be between $0.1-1 \times 10^{-2}$ to start the onboard generator when power demand outnumbers the battery capacity.

The values of the weight factors and their recommended ranges are shown in Table 2.

Table 2. The default values and recommended ranges of the designed weight factors.

\begin{tabular}{lcccccc}
\hline & $w_{v}$ & $w_{I_{M}}$ & $w_{F_{B r k}}$ & $w_{I_{S C}}$ & $w_{U_{C}}$ & $w_{q_{I C E}}$ \\
\hline Default values & 60 & 0.2 & 0.1 & 0.2 & 1 & $3 \times 10^{-3}$ \\
Suggested ranges & $30-100$ & $>0.1$ & $0.5-0.7$ of $w_{I_{M}}$ & $0.1-1.0$ & $0.1-2$ & $<1 \times 10^{-2}$ \\
\hline
\end{tabular}

\section{Additional costs}

Besides the penalties existing in functions of Eq. (18) and (21), the following costs are under consideration occasionally:

$$
\begin{aligned}
& J_{I_{B}}=w_{I_{B}} I_{B, k+1}^{2} R_{B}, \\
& J_{S o C_{B}}=\left(w_{S o C_{B}} Q_{B, \max }^{2} / C_{B}\right)\left(\left(\operatorname{SoC}_{B, k}+\left(\Delta T / Q_{B, \max }\right) I_{B, k+1}\right)-1\right)^{2}
\end{aligned}
$$

where the parameter $\mathrm{C}_{\mathrm{B}}$ is the battery capacitance. The cost $\mathrm{J}_{\mathrm{I}_{\mathrm{B}}}$ helps diminish the battery charge and discharge activity and $\mathrm{J}_{\mathrm{SoC}_{\mathrm{B}}}$ makes it easy to start the range extender. The rules for modification of the cost functions (18) and (21) using additional costs are as listed below.

i. If $\mathrm{SoC}_{\mathrm{B}}>35 \%$ and $\mathrm{N}_{\mathrm{RE}}=0$, then $\mathrm{w}_{\mathrm{I}_{\mathrm{B}}}=0$ and $\mathrm{w}_{\mathrm{SoC}_{\mathrm{B}}}=0$.

ii. If $\left(\mathrm{v}_{\mathrm{ref}, \mathrm{k}+1}-\mathrm{v}_{\mathrm{k}}\right) / \Delta \mathrm{T} \leq-3 \mathrm{~m} / \mathrm{s}^{2}$ and $\mathrm{U}_{\mathrm{C}, \mathrm{k}}-\mathrm{U}_{\mathrm{C}, \mathrm{KE}}\left(\mathrm{v}_{\mathrm{k}-1}\right) \leq-2 \mathrm{~V}$, then $\mathrm{w}_{\mathrm{I}_{\mathrm{B}}}=5$ and $\mathrm{w}_{\mathrm{U}_{\mathrm{C}}}=$ 0.1 .

iii. If $\mathrm{m}_{\mathrm{RE}, \mathrm{k}}^{\text {fuel }}>01$ and $\mathrm{v}_{\mathrm{k}} \geq 8 \mathrm{~m} / \mathrm{s}$, and $\mathrm{SoC}_{\mathrm{B}, \mathrm{k}} \leq 30 \%$, or $\mathrm{SoC}_{\mathrm{B}, \mathrm{k}} \leq 35 \%$ and $\mathrm{N}_{\mathrm{RE}, \mathrm{k}} \geq 100$ $\mathrm{rad} / \mathrm{s}$, then $\mathrm{w}_{\mathrm{SoC}_{\mathrm{B}}}=0.005$.

The first rule defines the default operation of the car: a charge depleting mode. The second rule regulates the SC bank to absorb only regenerative power during radical braking. The last rule governs the range extender concerning the noise levels.

\section{SIMULATION AND DISCUSSION}

A performance test of the proposed PMS, as well as a dynamic vehicle model development, was carried out in a Matlab/Simulink® environment. The 2-L, 4-stroke Volkswagen engine [42] was modelled using two lookup tables. The generator and traction motor were approximated using DC motor models. The EV model is based on the BMW i3 REx with 64-Ah Li-ion battery pack [39], and the SC bank based on the Maxwell supercapacitor module for heavy transportation [44]. The optimisation program 
can deal with $95 \%$ of the maximum motor current, while the other $5 \%$ is set aside for the speed controller to reject external disturbances. The studied car weighs $1415 \mathrm{~kg}$.

\section{Acceleration Test}

Figure 3 shows a reference speed profile and the car speed in an acceleration test. The studied car model could accelerate as fast as the BMW i3 REx, i.e., the car model accelerated from a stop to $100 \mathrm{~km} / \mathrm{h}$ in $7.95 \mathrm{~s}$, and from 80 to $120 \mathrm{~km} / \mathrm{h}$ in $5.53 \mathrm{~s}$. Thus, our model was sufficiently accurate when considered regarding acceleration performance.

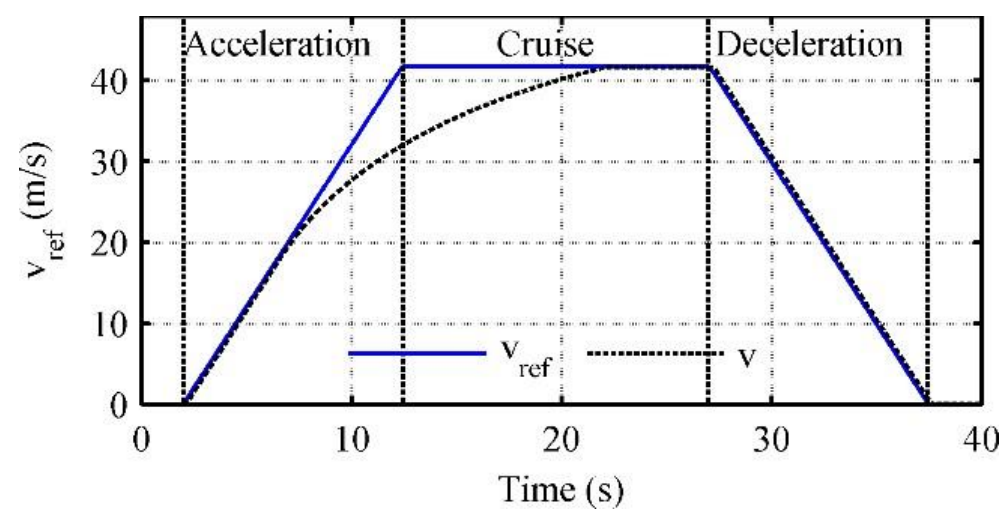

Figure 3. Speed profile of an acceleration test and the measured speed of the car. A set acceleration is $4 \mathrm{~m} / \mathrm{s}^{2}$, and a top speed is $41.8 \mathrm{~m} / \mathrm{s}(150 \mathrm{~km} / \mathrm{h})$.

The car components operated within their permissible ranges when the proposed PMS was employed. High-power demand was allocated to the energy storage devices appropriately. As a result, the traction motor produced enough driving torque to push the car to move forward rapidly.

The traction motor and friction brakes collaborated during braking to follow a requested speed and maximised recuperative power. Using the SC bank resulted in the diminution of the battery load and a higher capacity for absorbing recovered power. Also, the battery current stress declined because of the range extender assisting other energy storage devices when peak power demand happened. However, aggressive braking was problematic. It caused the SC bank to require high power for maintaining $U_{C}$ close to $U_{C, K E}$. Consequently, the SCs absorbed all regenerative power and drew considerable power from the battery pack (Figure 4 (a)). This high energy absorption led to additional losses and needed to be attenuated. Figure 4 (b) reveals that the SC bank stopped devouring vast power during radical braking because of the strategy devised in Section 3. The SC bank gradually drew electricity from the battery to keep perfect pace with $U_{C, K E}$, after a braking event had passed. 


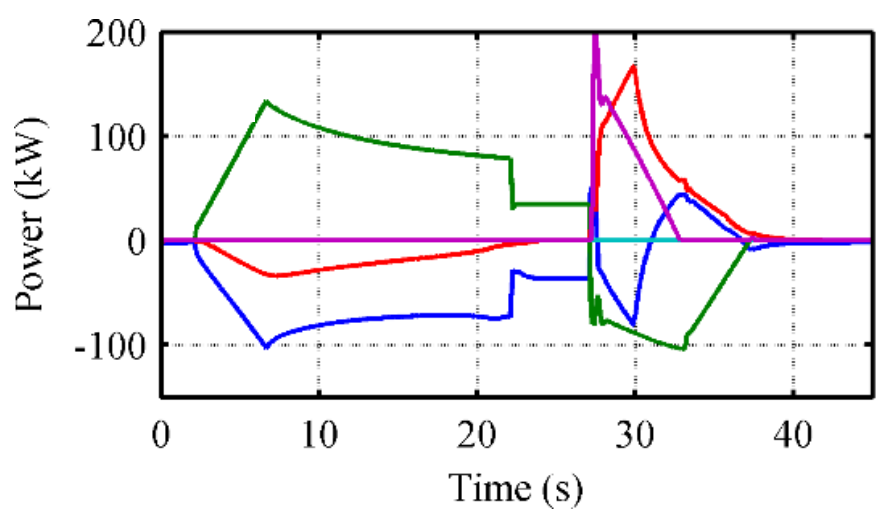

(a)

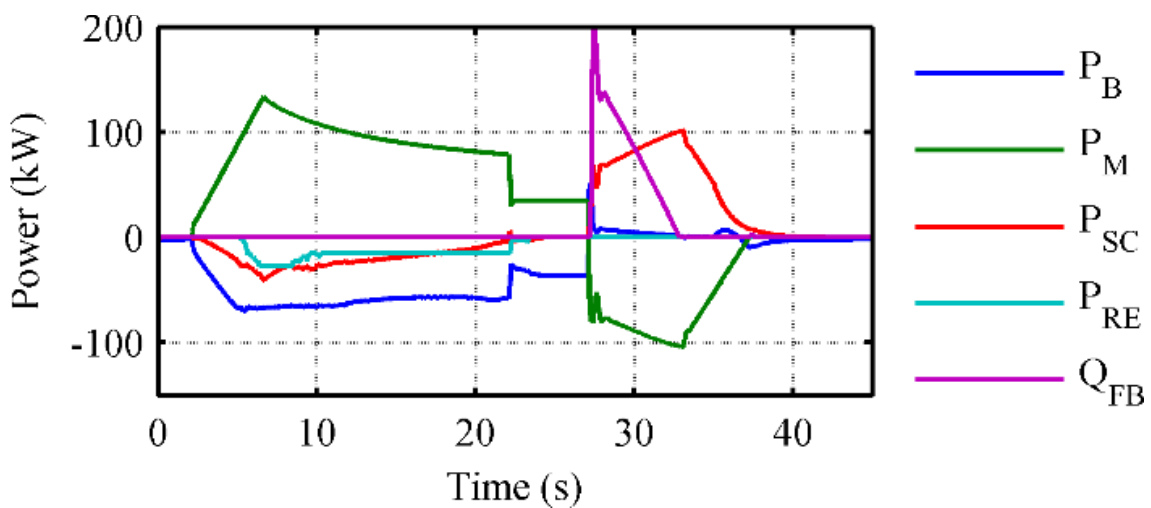

(b)

Figure 4. Electric power and heat dissipated by mechanical brakes, denoted by $Q_{F B}$, when the PMS implements (a) the original control strategy, and (b) the proposed control strategy. Note that the car was tested under the defined acceleration test.

\section{Standardised Driving Cycles}

Figure 5 presents the total mileage and energy consumption when the car is tested under a long driving cycle. At the start, the state of charge was $90 \%$, and the car was working in a charge-depleting mode. The range extender was first run after the car had already traveled $81 \mathrm{~km}$. Since then, the vehicle operated in a charge-sustaining mode until the car run out of fuel. An all-electric range was $101 \mathrm{~km}$, and an extended range was $243 \mathrm{~km}$. The fuel efficiency of the ICE was 36\%, and the car consumed 4.12 liters per $100 \mathrm{~km}$.

Table 3 presents approximated all-electric ranges, calculated based on $18.8 \mathrm{kWh}$ of usable battery capacity. This mileage is acceptable for most sampled drivers in references [45], [46] since an average daily distance they travel is shorter than $80 \mathrm{~km}$.

\section{Performance Comparison between Two Optimisation Programs}

Future behaviour of the car's components was considered in the NMPC-based program. Thus, the responses of the vehicle improved. This work selects a $10-\Delta T$ predictive horizon-- $T_{P}=10 \Delta T$-- according to a piece of advice in [47].

As shown in Figure 6, the NMPC-based program cancelled out speed deviation quicker and diminished a steady-state speed error better than the CQP. Nevertheless, the magnitude of a steady-state error from these programs was hard to distinguish by drivers. Figure 7 reveals that the NMPC-based program outperforms the CQP in regulating the 
car's components. The NMPC-based program could make use of the SC bank more active. However, the SC power profiles develop similarly in both graphs in Figure 7, which means that these programs can keep track of the reference SC energy level equally.

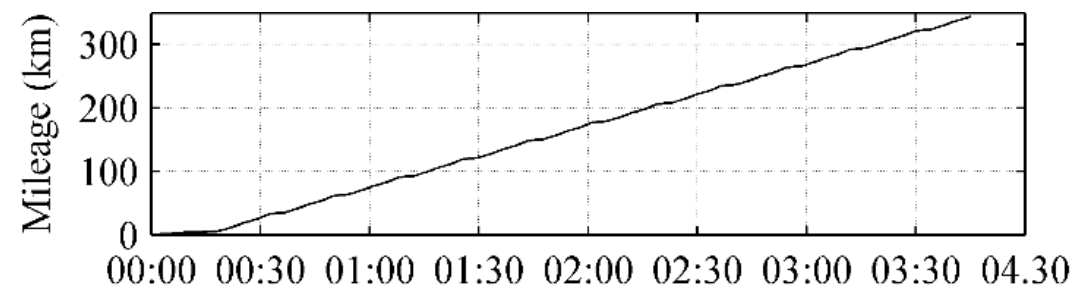

(a)

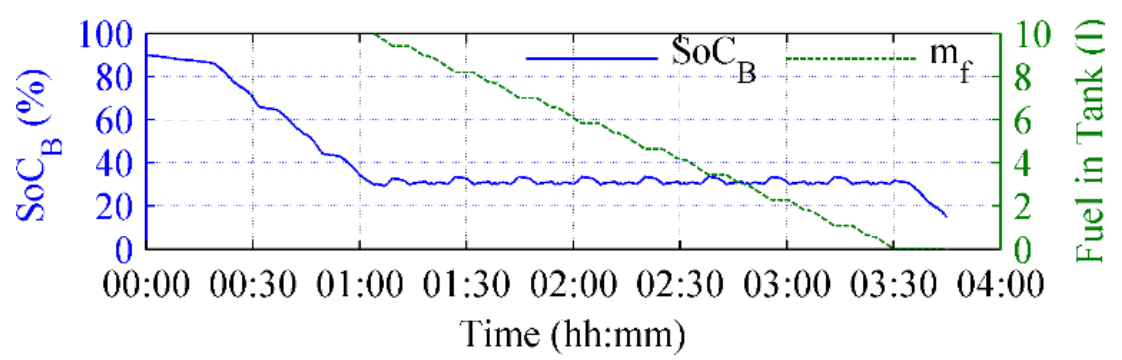

(b)

Figure 5. (a) Evolutions of mileage and (b) a battery state of charge along with fuel usage under one Artemis urban and repeated Artemis motorway cycles. The simulation was carried out until a fuel tank was empty, and a battery state of charge was below $15 \%$.

Table 3. Rates of energy expenditure under two different standardised driving cycles.

\begin{tabular}{lccc}
\hline Cycles & $\begin{array}{c}\text { Total consumption } \\
(\mathrm{kWh} / 100 \mathrm{~km})\end{array}$ & $\begin{array}{c}\text { Total resistive losses } \\
(\mathrm{kWh} / 100 \mathrm{~km})\end{array}$ & $\begin{array}{c}\text { Approx. all-electric } \\
\text { range }(\mathrm{km})\end{array}$ \\
\hline $\begin{array}{l}\text { Artemis urban } \\
\begin{array}{l}\text { Artemis } \\
\text { motorway }\end{array}\end{array}$ & 13.69 & 0.90 & 127 \\
\hline
\end{tabular}

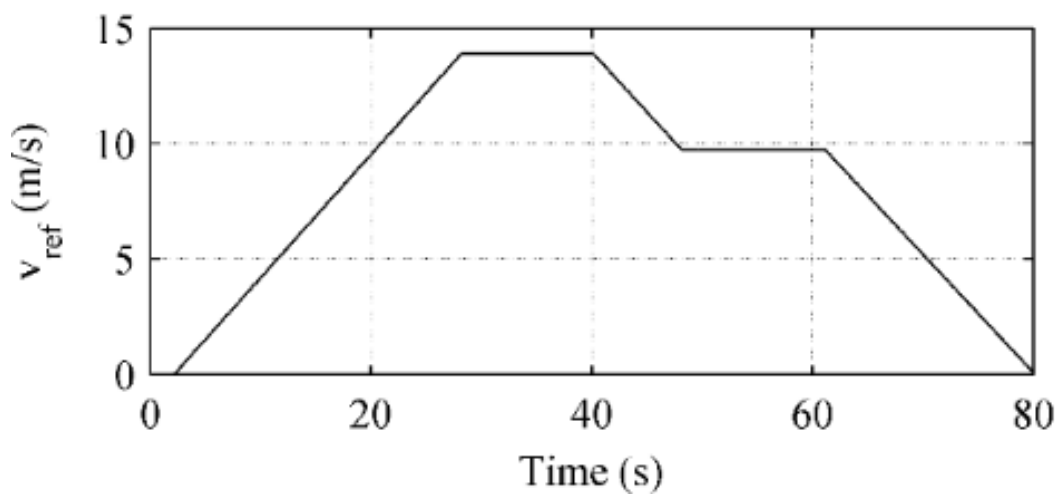

(a) 


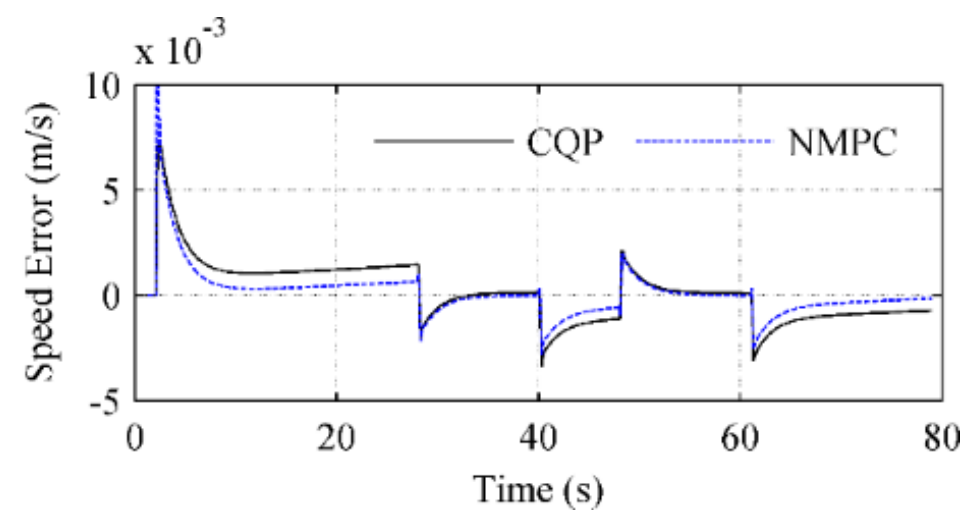

(b)

Figure 6. (a) A reference speed and (b) speed deviation when the CQP and NMPCbased program are utilized.

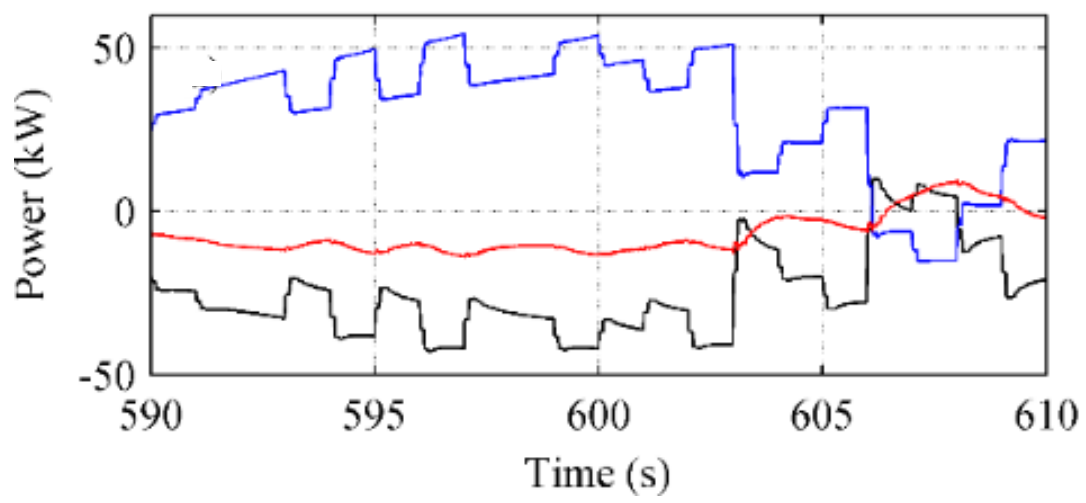

(a)

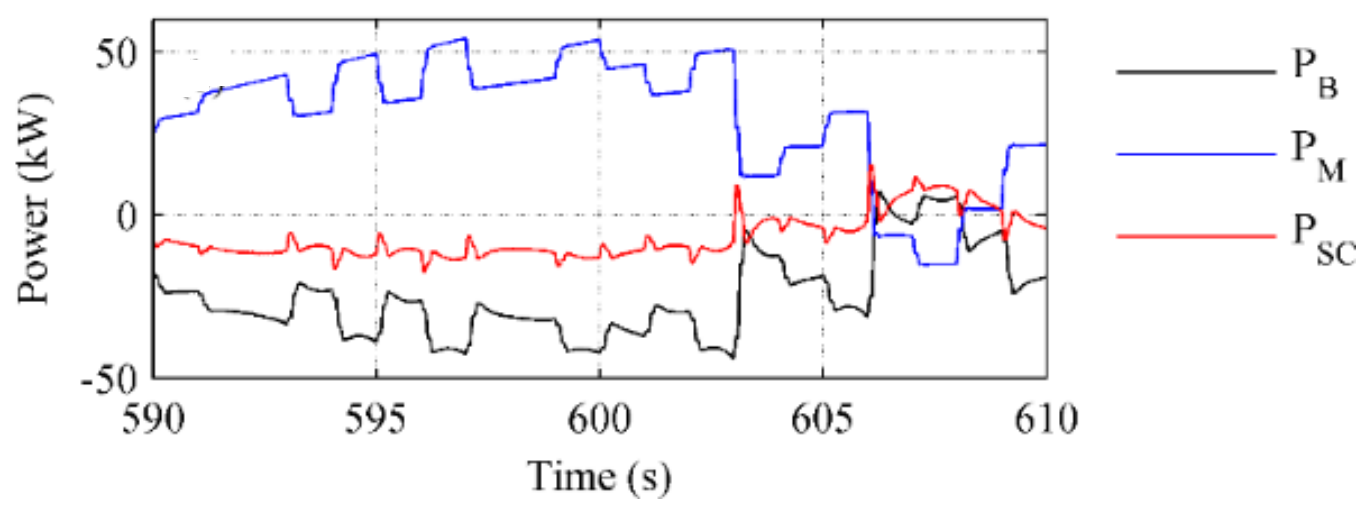

(b)

Figure 7. Power evolutions of the vehicle supervised by (a) the CQP and (b) NMPCbased program.

As presented in Figure 8, there is no significant difference when the CQP and the NMPC-based program are compared based on energy usage. Battery states of charge trajectories from these programs were close to each other. The CQP performed slightly better in the Artemis motorway, whereas the NMPC-based program ended the trip with higher electricity stored in the primary source. Furthermore, overall energy consumption from these programs resembled each other. 


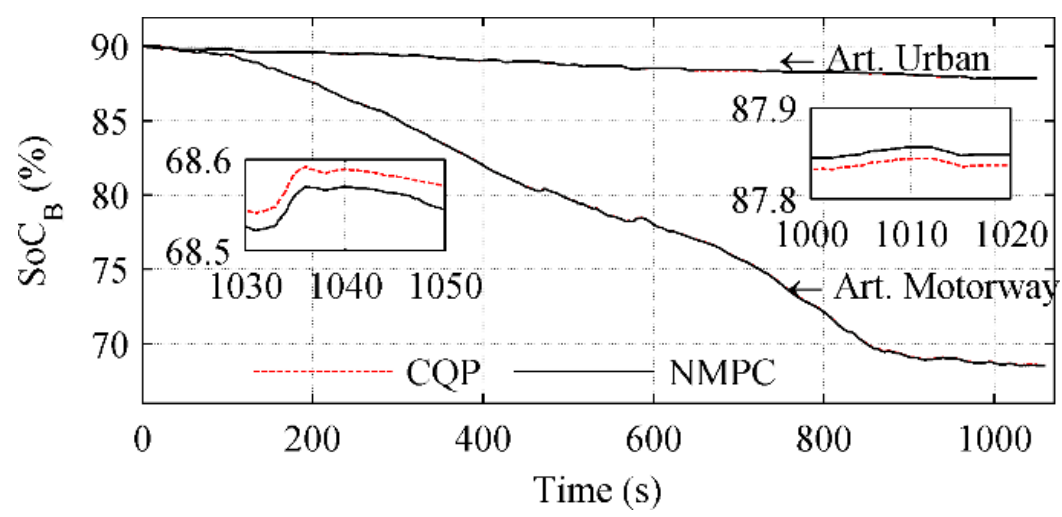

Figure 8. A comparison of the state of charge between the NMPC-based program and CQP.

\section{CONCLUSION}

From the simulation study, the following conclusions are drawn:

i. The proposed CQP-based PMS allocated optimal power loads to the car components appropriately without violating any physical constraints.

ii. Effective adaptation of the range extender made the battery current stress less intense when peak power demand occurred.

iii. Weight factors were powerful tools for influencing the optimization program to achieve some goals, such as recharging the SC bank using only regenerative power.

iv. The CQP could achieve optimal energy consumption, comparable to the NMPCbased program.

The CQP solver took a relatively long time to satisfy quadratic constraints and handle integer variables. Linearization of the quadratic constraint will decrease computation time and increase opportunities to apply this program to online applications. In the future, a hardware-in-the-loop simulation will be carried out to validate the performance of the proposed PMS.

\section{ACKNOWLEDGEMENT}

The authors are thankful for all valuable support from the Institute for Mobile Systems, Otto-von-Guericke-University Magdeburg, Magdeburg, and Prince of Songkla University, Songkhla.

\section{REFERENCES}

[1] Zhang X, Mi C. Vehicle power management. London: Springer London; 2011.

[2] Does imported oil threaten U.S. national security? Retrieved from https://www.rand.org/pubs/research_briefs/RB9448/index1.html; 31 May, 2017.

[3] Energy use for transportation - energy explained, your guide to understanding energy - energy information administration. Retrieved from https://www.eia.gov/energyexplained; 31 May, 2017. 
[4] Oil and petroleum products - a statistical overview - statistics explained, Eurostat: statistics explained. Retrieved from http://ec.europa.eu/eurostat/statisticsexplained; 31 May, 2017.

[5] Mahmoudzadeh AA, Pesiridis A, Rajoo S, Martinez-Botas R, Esfahanian V. A review of battery electric vehicle technology and readiness levels. Renewable and Sustainable Energy Reviews, 2017; 78, 414-430.

[6] Tamilselvan P, Nallusamy N, Rajkumar S. A comprehensive review on performance, combustion and emission characteristics of biodiesel fuelled diesel engines. Renewable and Sustainable Energy Reviews, 2017; 79, 1134-1159.

[7] Hulwan DB, Joshi SV. Multizone model study for DI diesel engine running on diesel-ethanol-biodiesel blends of high ethanol fraction. International Journal of Automotive and Mechanical Engineering, 2018; 15(3), 5451-5467.

[8] Abdullah Z, Suhaimi H, Abdullah A, Taufik MF, Mrwan AG. Effect of pentanoldiesel fuel blends on thermo-physical properties, combustion characteristics, engine performance and emissions of a diesel engine. International Journal of Automotive and Mechanical Engineering, 2018; 15(3), 5435-5450.

[9] Anggono W, Noor MM, Suprianto FD, Lesmana LA, Gotama GJ, Setiyawan A. Effect of Cerbera manghas biodiesel on diesel engine performance. International Journal of Automotive and Mechanical Engineering, 2018; 15(3), 5667-5682.

[10] Nayak SK, Mishra PC. Analysis of a diesel engine fuelled with jojoba blend and coir pith producer gas. International Journal of Automotive and Mechanical Engineering, 2017; 14(4), 4675-4689.

[11] Pham XD, Noor MM, Hoang AT. Comparative analysis on performance and emission characteristic of diesel engine fueled with heated coconut oil and diesel fuel. International Journal of Automotive and Mechanical Engineering, 2018; 15(1), 5110-5125.

[12] Jiménez-Espadafor FJ, Guerrero DP, Trujillo EC, García MT, Wideberg J. Fully optimized energy management for propulsion, thermal cooling and auxiliaries of a serial hybrid electric vehicle. Applied Thermal Engineering, 2015; 91, 694-705.

[13] Techrules to display Ren supercar at prestigious Concorso D'Eleganza at the Villa D’Este. Retrieved from http://www.techrules-news.com/; 3 July, 2017.

[14] Wrightspeed range-extended electric powertrains. Retrieved from http://www.wrightspeed.com/; 3 July, 2017.

[15] Gissing J, Lichius T, Baltzer S, Hemkemeyer D, Eckstein L. Predictive energy management of range-extended electric vehicles considering cabin heat demand and acoustics. IFAC-PapersOnLine, 2015; 48(15), 209-216.

[16] Propfe B, Redelbach M, Santini DJ, Friedrich H. Cost analysis of plug-in hybrid electric vehicles including maintenance \& repair costs and resale values. In: EVS26 International Battery, Hybrid and Fuel Cell Electric Vehicle Symposium, California, USA, pp. 1-10; 2012.

[17] Pereirinha PG, Trovão JP. Multiple energy sources hybridization: the future of electric vehicles? In: Stevic Z, editor. New generation of electric vehicles, Rijeka: IntechOpen, 2012, p 237-264.

[18] Sandoval C, Alvarado VM, Carmona JC, Lopez CL, Gomez-Aguilar JF. Energy management control strategy to improve the FC/SC dynamic behavior on hybrid electric vehicles: a frequency based distribution. Renewable Energy, 2017; 105, 407-418. 
[19] Hwang JJ, Chen YJ, Kuo JK. The study on the power management system in a fuel cell hybrid vehicle. International Journal of Hydrogen Energy, 2012; 37(5), 4476-4489.

[20] Hannan MA, Azidin FA, Mohamed A. Multi-sources model and control algorithm of an energy management system for light electric vehicles. Energy Conversion and Management, 2012; 62, 123-130.

[21] Chen BC, Wu YY, Tsai HC. Design and analysis of power management strategy for range extended electric vehicle using dynamic programming. Applied Energy, 2014; 113, 1764-1774.

[22] Zhang S, Xiong R. Adaptive energy management of a plug-in hybrid electric vehicle based on driving pattern recognition and dynamic programming. Applied Energy, 2015; 155, 68-78.

[23] Sorrentino M, Rizzo G, Arsie I. Analysis of a rule-based control strategy for onboard energy management of series hybrid vehicles. Control Engineering Practice, 2011; 19(12), 1433-1441, 2011.

[24] Li Q, Chen W, Li Y, Liu S, Huang J. Energy management strategy for fuel cell/battery/ultracapacitor hybrid vehicle based on fuzzy logic. International Journal of Electrical Power \& Energy Systems, 2012; 43(1), 514-525.

[25] Chen BC, Guan JC, Li JH. Adaptive power management control of range extended electric vehicle. Energy Procedia, 2014; 61, 67-70.

[26] Chen Z, Xiong R, Wang C, Cao J. An on-line predictive energy management strategy for plug-in hybrid electric vehicles to counter the uncertain prediction of the driving cycle. Applied Energy, 2017; 185(Part 2), 1663-1672.

[27] Zeng X, Wang J. A two-level stochastic approach to optimize the energy management strategy for fixed-route hybrid electric vehicles. Mechatronics, 2016; 38, 93-102.

[28] Kelouwani S, Agbossou K, Dubé Y, Boulon L. Fuel cell plug-in hybrid electric vehicle anticipatory and real-time blended-mode energy management for battery life preservation. Journal of Power Sources, 2013; 221, 406-418.

[29] Murgovski N, Johannesson L, Sjöberg J, Egardt B. Component sizing of a plugin hybrid electric powertrain via convex optimization. Mechatronics, 2012; 22(1), 106-120.

[30] $\mathrm{Hu} \mathrm{X}$, Johannesson L, Murgovski N, Egardt B. Longevity-conscious dimensioning and power management of the hybrid energy storage system in a fuel cell hybrid electric bus. Applied Energy, 2015; 137, 913-924.

[31] Nüesch T, Elbert P, Flankl M, Onder C, Guzzella L. Convex optimization for the energy management of hybrid electric vehicles considering engine start and gearshift costs. Energies, 2014; 7(2), 834-856.

[32] Chen Z, Xia B, You C, Mi CC. A novel energy management method for series plug-in hybrid electric vehicles. Applied Energy, 2015; 145, 172-179.

[33] Chen Z, Mi CC, Xiong R, Xu J, You C. Energy management of a power-split plug-in hybrid electric vehicle based on genetic algorithm and quadratic programming. Journal of Power Sources, 2014; 248, 416-426.

[34] Grüne L, Pannek J, Nonlinear Model Predictive Control. London: Springer London; 2011.

[35] Zhang S, Xiong R, Sun F. Model predictive control for power management in a plug-in hybrid electric vehicle with a hybrid energy storage system. Applied Energy, 2017; 185(Part 2), 1654-1662. 
[36] Xiang C, Ding F, Wang W, He W. Energy management of a dual-mode powersplit hybrid electric vehicle based on velocity prediction and nonlinear model predictive control. Applied Energy, 2017; 189, 640-653.

[37] Achterberg T. SCIP: solving constraint integer programs. Mathematical Programming Computation, 2009; 1(1), 1-41.

[38] Alexander A, Vacca A. Longitudinal vehicle dynamics model for construction machines with experimental validation. International Journal of Automotive and Mechanical Engineering, 2017; 14(4), 4616-4633.

[39] BMW i3: Technical data. Retrieved from http://www.bmw.com/; 31 May, 2016.

[40] Armenta J, Núñez C, Visairo N, Lázaro I. An advanced energy management system for controlling the ultracapacitor discharge and improving the electric vehicle range. Journal of Power Sources, 2015; 284, 452-458.

[41] Jarushi AM, Schofield N. Battery and supercapacitor combination for a series hybrid electric vehicle. In: 5th IET International Conference on Power Electronics, Machines and Drives (PEMD 2010), Brighton, UK; pp. 1-6; 2010.

[42] Hadler DIJ, Rudolph DIF, Engler DIHJ, Röpke DIS. Der neue 2,0-1-4V-TDIMotor mit Common-Rail-Einspritzung. MTZ Motortech Z, 2007; 68(11), 914923.

[43] OPTI Toolbox Wiki. Retrieved from http://www.i2c2.aut.ac.nz/Wiki/OPTI/; 24 Apr, 2016.

[44] Maxwell Technologies 125 Volt Transportation Modules Ultracapacitors Application Specific Modules. Retrieved from http://www.maxwell.com; 19 January, 2017.

[45] Pearre NS, Kempton W, Guensler RL, Elango VV. Electric vehicles: how much range is required for a day's driving? Transportation Research Part C: Emerging Technologies, 2011; 19(6), 1171-1184.

[46] Franke T, Krems JF. What drives range preferences in electric vehicle users? Transport Policy, 2013; 30, 56-62.

[47] Choose Sample Time and Horizons - MATLAB \& Simulink. Retrieved from https://www.mathworks.com/help/mpc/ug/choosing-sample-time-and-

horizons.html.; 8 July, 2018. 